\title{
THEORETICAL ANALYSIS OF INTERACTION ENERGY IN ALGINATE-CAPPED GOLD NANOPARTICLES COLLOIDAL SYSTEM
}

\author{
Foliatini ${ }^{1}$, Yoki Yulizar ${ }^{1, *}$, and Mas Ayu Elita Hafizah ${ }^{2}$ \\ ${ }^{1}$ Department of Chemistry, Faculty of Mathematics and Natural Sciences, Universitas Indonesia \\ Depok 16424, Indonesia \\ ${ }^{2}$ PT. Clariant Indonesia, Tangerang 15138, Indonesia
}

Received May 21, 2014; Accepted July 27, 2014

\begin{abstract}
Stability of Au/alginate nanocomposite was theoretically evaluated by computing various interactions energy which contributes in the system, including attraction and repulsion interaction. The results revealed that both polymer and electrostatic charges play a significant role in the stabilization, but the steric repulsion comes from polymer chain is a more effective stabilization mechanism than the electrostatic repulsion. Higher $\mathrm{pH}$ yielded in stronger electrostatic repulsion but when the alginate thickness is low the resulting nanocomposite was less stable in a long time period. Interaction energies for Au/alginate nanocomposite colloidal system was up to $\sim 60 \mathrm{kT}$ for alginate thickness of $1 \mathrm{~nm}$, at very short particle-particle separation distance $(<1 \mathrm{~nm})$. As the alginate thickness can be controlled by adjusting the alginate concentration, it can be concluded that the high stability of Au/alginate nanocomposite can be achieved by employing an appropriate amount of alginate concentration.
\end{abstract}

Keywords: Au/alginate nanocomposite; van der Waals energy; steric repulsion energy; electrostatic energy

\section{ABSTRAK}

Stabilitas nanokomposit Au/alginat telah dipelajari secara teoritis dengan menghitung energi interaksi yang memiliki kontribusi di dalam sistem, termasuk interaksi tarik-menarik dan tolak-menolak. Hasil penelitian menunjukkan bahwa baik polimer maupun muatan elektrostatik memainkan peranan penting dalam stabilisasi, namun tolakan sterik yang berasal dari rantai polimer merupakan mekanisme stabilisasi yang lebih efektif dibandingkan dengan tolakan elektrostatik. pH yang lebih tinggi menghasilkan tolakan elektrostatik yang lebih kuat namun jika ketebalan lapisan alginat rendah maka nanokomposit yang dihasilkan kurang stabil dalam waktu yang lama. Energi interaksi untuk sistem koloid nanokomposit Au/alginat dapat mencapai sebesar $\sim 60 \mathrm{kT}$ untuk ketebalan lapisan alginat $1 \mathrm{~nm}$, pada jarak pemisahan partikel-partikel yang sangat pendek $(<1 \mathrm{~nm})$. Karena ketebalan lapisan alginat dapat dikontrol dengan mengatur konsentrasi lapisan alginat, dapat disimpulkan bahwa kestabilan nanokomposit Au/alginat dapat dicapai dengan menggunakan konsentrasi alginat yang sesuai.

Kata Kunci: nanokomposit Au/alginat; energi van der Waals; energi tolakan sterik; energi elektrostatik

\section{INTRODUCTION}

Interaction forces between colloidal particles, including nanoparticles in suspension, emulsion, and aqueous dispersion, play a great role in determining various material properties, such as mechanical properties, reactivity, and interfacial properties. This arises due to the dependence of the behavior of the suspensions/emulsions on the magnitude and range of the surface interactions [1]. From the kinetics view points, interparticle interaction can influence the kinetics of self-assembly of coating material onto the particle surface [2].

Thermodynamically, colloidal dispersion represents a state of higher free energy than aggregated state.
Coagulation/flocculation, states of lower free energy, will occur spontaneously unless there is a substantial energy barrier preventing this tendency [3]. Aggregation reduces the specific surface area and interfacial free energy, and these phenomenons significantly reduce the particles reactivity [4].

To control the magnitude of interaction energies between particles in a colloidal dispersion, it is required to understand all of interaction types that affect the colloidal stability, including attraction and repulsion interaction. The more various the components which contribute in the dispersion system, such as polymers, surfactant, ions, the more complicated the interaction, and thus the calculation of total interaction energy. By describing each possible interaction into mathematical

* Corresponding author. Tel/Fax : +62-21-7270027/7863432

Email address : yokiy@ui.ac.id

Foliatini et al. 
equation, the relation between each variable which has contribution in the interaction can be explained, and furthermore the factors that influence the strength of the interaction can be finely understood.

\section{EXPERIMENTAL SECTION}

\section{Materials}

Au/alginate nanocomposite studied in this experiment were synthesized in the condition such below. $0.20 \mathrm{mM} \mathrm{AuCl}_{4}^{-}$solution (prepared from dissolving $\mathrm{Au} 99.9 \%$ in aqua regia followed by an appropriate purification and dilution step) was used as $\mathrm{Au}$ precursor. Alginate biopolymer (> 90\% purity, Himedia) was used as reducing agent and stabilizer. Alginate concentration of $0.375 \%(\mathrm{w} / \mathrm{v})$ was used in the synthesis. $\mathrm{HCl}$ and $\mathrm{NaOH}$ were used for adjusting $\mathrm{pH}$.

\section{Instrumentation}

The optical extinction spectra were measured by an ultraviolet-visible (UV-Vis) spectrophotometer (UV-1700, Shimadzu) in a scanning range of $190 \mathrm{~nm}$ to $1100 \mathrm{~nm}$. The morphologies of the Au-NP were observed by transmission electron microscopy (TEM) on JEM-1400 electron microscope JEOL instrument by operating at an accelerating voltage of $120 \mathrm{kV}$. The particle size, particle size distribution and zeta potential were evaluated by Particle Size Analyzer (Malvern Zetasizer, ZEN-1600 for particle size and size distribution, Malvern Zetasizer Nano ZS for zeta potential).

\section{Procedure}

Nanocomposite was synthesized using bottom-up technique in the presence of alginate as reducing agent with the aid of microwave energy to accelerate nucleation and growth process and increase particle size homogeneity. Briefly, $10 \mathrm{~mL}$ of $\mathrm{HAuCl}_{4}$ solution was poured into $100 \mathrm{~mL}$ beaker glass and added by $10 \mathrm{~mL}$ of alginate solution. The mixture was irradiated for some minutes until the color of the solution was changed. The final solution was cooled in room temperature before further characterization. $\mathrm{pH}$ was adjusted in the range of $2-10$. The alginate concentration was varied in the range of $0.075-0.375 \%(\mathrm{w} / \mathrm{v})$ and the stability of the asprepared nanocomposites were examined from the SPR characteristics, particle size and TEM images. The data yielded from the experiment, including particle size, zeta potential and the concentration of each ions, were used for further theoretical calculation using mathematical equation of relevant interaction energy.

\section{RESULT AND DISCUSSION}

Alginate was utilized in the experiment since it belongs to biopolymer which provides a bulk chain structure that is potential for capping nanoparticles. Moreover, several biopolymers were reported to be potential reducing agent [5-8], therefore introducing these materials in the synthesis can minimize the steps of the synthesis procedures.

The results showed that the particle size of the nanocomposite were in the range of 2-10 nm for Au/alginate depending on several variables including metal precursor concentration, alginate concentration, and $\mathrm{pH}$. These nanocomposites were relatively stable until 7 months after preparation, without any signs of aggregation. The results also revealed that the higher the alginate concentration, the higher the stability of the nanocomposites, thus the smaller the particle size. The phenomena confirmed the role of alginate as stabilizer. Another information implied from the experiment was that the $\mathrm{pH}$ could effectively influence electrostatic interaction between particles, resulting in smaller particle size with the increase of $\mathrm{pH}$. It can be suggested that electrostatic interaction played a significant role in stabilizing colloidal system of the nanocomposites.

In the next section, both the steric energy comes from repulsion between alginate chain and electrostatic energy comes from repulsion between the same charges were calculated using the mathematical equation derived from literature [3]. Those energies were plotted as a function of particle-particle separation distance and the values were used to explain how much the contribution of each interaction in the nanocomposites stabilization.

\section{Stabilization Energy of Four Au/Alginate Nanocomposite Colloidal System}

In the synthesis of nanocomposite Au/alginate studied in this research, alginate has function not only as reducing agent but also as modifier and stabilizer for the as-prepared nanocomposites. The bulk chain of alginate biopolymer was arranged in a compact structure on the surface of nanoparticles to make a barrier for van der Waals attraction between particles. Besides polymer chains, ions were also present in this system, comes from $\mathrm{HCl}$ and $\mathrm{NaOH}$ as $\mathrm{pH}$ adjusting solution. These ions played the same role of stabilizing agent via electrostatic repulsion. As both the polymer and ions were used in the stabilization mechanism, it can be predicted that both electrostatic and steric interaction energy were present. Even though the electrostatic and steric repulsion energy are not completely independent [9], to estimate the stabilization 

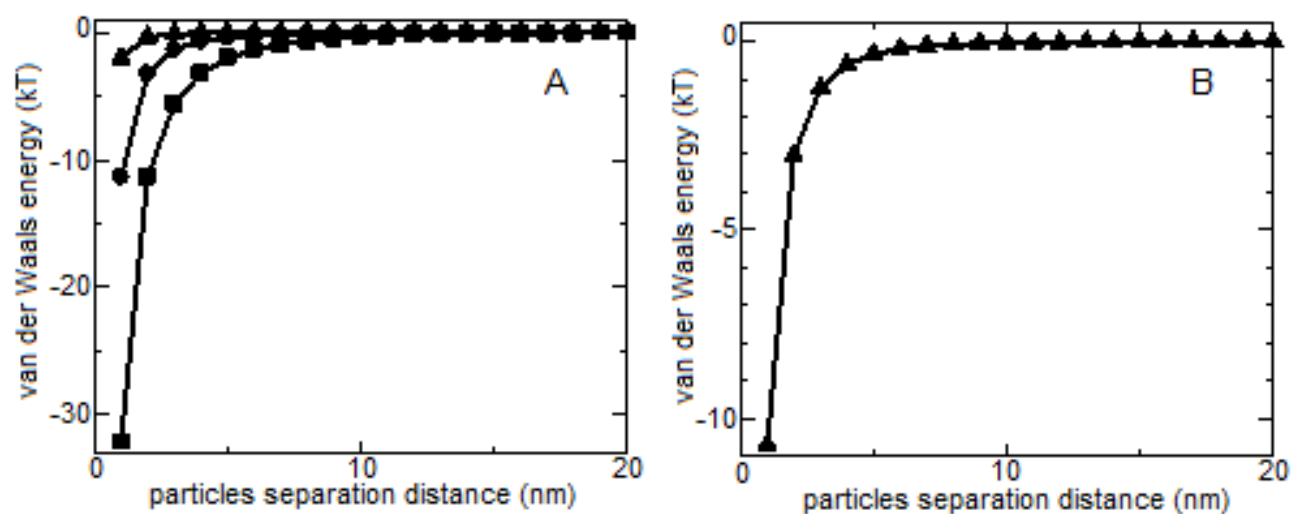

Fig 1. A. $E_{v d w}(h)$ curve for Au/alginate nanocomposite at various particle size $(a=2,5,10 \mathrm{~nm}$, from top to bottom). B. $E_{\mathrm{vdW}}(\mathrm{h})$ curve for Au/alginate nanocomposite at $\mathrm{a}=2.414 \mathrm{~nm}$ (synthesized at $\mathrm{pH} 10$ )

energy for colloidal Au/alginate nanocomposite system, it can be assumed that the interaction energies are additive. Therefore the total energy is the sum of van der Waals energy $\left(E_{\mathrm{vdw}}(h)\right)$, steric energy $\left(E_{\mathrm{es}}(h)\right)$, and electrostatic energy $\left(E_{\text {ster }}(h)\right)$ as stated below.

$$
E_{T}(h)=E_{v d w}(h)+E_{e s}(h)+E_{s t e r}(h)
$$

\section{Van der Waals energy}

Van der Waals attraction energy between particles can be calculated using equation 2. $A_{H}$ is Hamaker constant of interparticle interaction. The knowledge of the dielectric spectra over the entire frequency range for all of the individual materials comprising the system is required to calculate the values. For $\mathrm{Au}-\mathrm{Au}$ core the constant is found to be $45.3 \times 10^{-20} \mathrm{~J}$ [10]. Several calculation techniques were described in the literatures [11-12]. By using equation 2, van der Waals interaction energy for Au/alginate nanocomposite in the range of particle-particle separation distance $(h)$ from $0-20 \mathrm{~nm}$ can be calculated by assuming that the particle size at optimum condition was $4.828 \mathrm{~nm}$ or particle radius (a) was $2.414 \mathrm{~nm}$. Equation 2 is valid when the particles were spherical and have the same radius.

$E_{v d W}(h)=-\frac{A_{H}}{6}\left[\frac{2 a^{2}}{h^{2}+4 a h}+\frac{2 a^{2}}{(h+2 a)^{2}}+\ln \left(1-\frac{4 a^{2}}{(h+2 a)^{2}}\right)\right]$

The trends of van der Waals energy can be observed from Fig. 1A. Since the van der Waals interaction is attractive, $E_{\mathrm{vdw}}(\mathrm{h})$ is negative with infinite value as $\mathrm{h} \rightarrow 0$ and diminishes quickly as $\mathrm{h}$ increases. Based on equation 2, $E_{\mathrm{vdw}}(\mathrm{h})$ depends on particle size, and the larger the particle size, the more negative the $E_{\mathrm{vdw}}(\mathrm{h})$, indicated the higher tendency to interact between particles, leading to unavoiding aggregation. Therefore it required sufficient energy barrier to counteract the attraction that can be accomplished by applying polymer chain deposition on the particle surface or adjusting the concentration of ions to create repulsion between the same sign of charges.

\section{Electrostatic interaction energy}

Electrostatic interaction energy was calculated to predict the magnitude of repulsion interaction between electrical charges with opposite signs as the particles get closer. If the energy was so high that the summation between this energy and $E_{\mathrm{vdw}}(\mathrm{h})$ gives highly positive values, the aggregation would be hindered. Electrostatic energy depends on electric double layer thickness, $1 / \kappa$, which can be expressed as

$\kappa=\left(\frac{2 e^{2} N_{A}\left(1 / 2 c_{i} z_{i}^{2}\right)}{\varepsilon_{0} \varepsilon_{T} k T}\right)^{\frac{1}{2}}$

$e$ is electron charge, $N_{\mathrm{A}}$ is Avogadro's number, $\mathrm{c}$ is the molar concentration of ions, $z$ is the valency of each ions, $\varepsilon_{0}$ is the permittivity of free space $\left(8.854 \times 10^{-12} \mathrm{Fm}^{-1}\right), \varepsilon_{\mathrm{r}}$ is the dielectric constant of the suspension medium and is approximately 78.40 for an aqueous system at $20^{\circ} \mathrm{C}$.

Electrostatic interaction energy depends on zeta potential, i.e., the potential where the ions are less firmly bound to the particle surface (diffuse layer). One requirement for this energy calculation is that the zeta potential should be $<50 \mathrm{mV}$, so that in the studied system, colloidal Au/alginate nanocomposite with zeta potential of about $-30 \mathrm{mV}$ or lower, this energy can be well explained. When $\kappa$ a $>10$, electrostatic repulsion energy is defined as,

$E_{e s}(h)=2 \pi \varepsilon_{r} \varepsilon_{0} a \xi^{2} \ln [1+\exp (-\kappa h)]$

When the electric double layer around the particles is very extensive such that $\kappa a<5$, the above equation is not valid and need to be rearranged such below,

$E_{e s}(h)=2 \pi \varepsilon_{r} \varepsilon_{0} a \xi^{2}[\exp (-\kappa h)]$

In the studied system, stabilization energies were calculated for Au/alginate nanocomposites which have particle size relatively small, synthesized using experimental conditions as follows, $\mathrm{AuCl}_{4}^{-} 0.20 \mathrm{mM}$, alginate concentration of $0.375 \%(\mathrm{w} / \mathrm{v})$ and $\mathrm{pH} 10$. The 

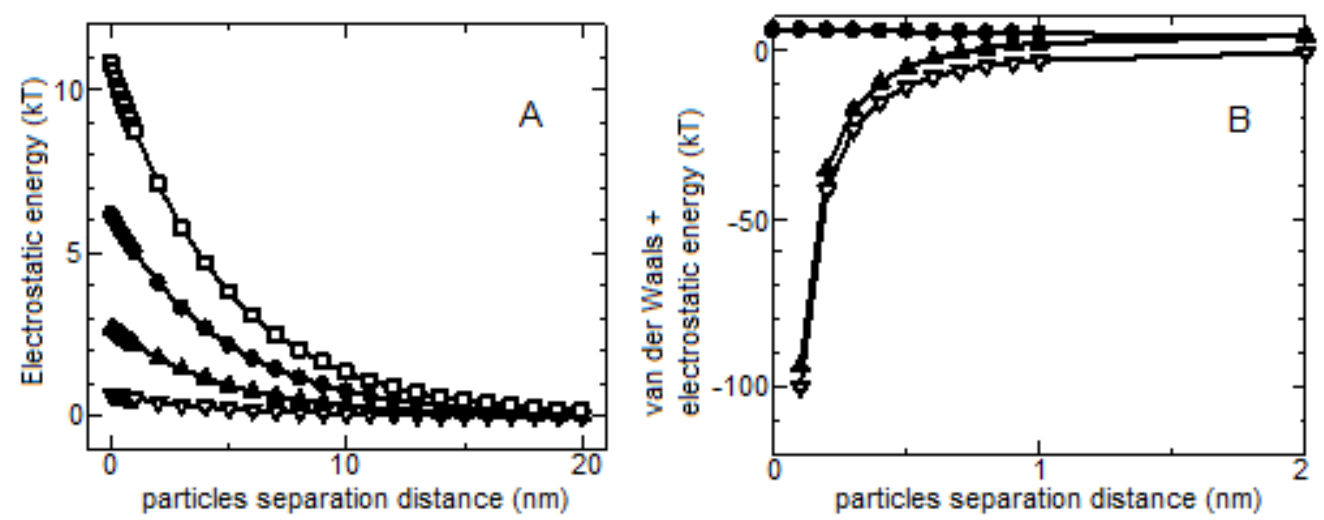

Fig 2. A. Electrostatic repulsion energy for colloidal Au/alginate nanocomposite at various zeta potential $(-30,-27$, $-25,-22,-11.5,-7 \mathrm{mV}$, from top to bottom), B. electrostatic repulsion energy for colloidal Au/alginate nanocomposite at zeta potential $=-30 \mathrm{mV}(\boldsymbol{\bullet})$, van der Waals energy $(\mathbf{\Delta})$, and total energy (van der Waals + electrostatic energy) $(\nabla)$



Fig 3. Zeta potential distribution curve for Au/alginate nanocomposite at various $\mathrm{pH}$ (nanocomposite was synthesized at $\left[\mathrm{AuCl}_{4}\right]=0.20 \mathrm{mM}$, [alginate $\left.]=0.375 \%(\mathrm{w} / \mathrm{v})\right)$

Table 1. Zeta potential and particle size of Au/alginate nanocomposite at various $\mathrm{pH}$

\begin{tabular}{ccc}
\hline $\mathrm{pH}$ & Zeta potential $(\mathrm{mV})$ & Particle size $(\mathrm{nm})$ \\
\hline 2 & -7.18 & 16.36 \\
4 & -11.3 & 91.41 \\
6 & -22.4 & 19.74 \\
8 & -25.8 & 8.501 \\
10 & -30.3 & 5.464 \\
& & 4.828 \\
\hline
\end{tabular}

as-synthesized Au/alginate nanocomposite has particle size of $4.828 \mathrm{~nm}(\mathrm{a}=2.414 \mathrm{~nm})$ and since the $\kappa$ is 0.2087 , thus ка is 0.5038 or $<5$, and only equation 5 is applicable to describe this system.

From the results, it was found that the zeta potential of the nanocomposite was negative and became more negative as the $\mathrm{pH}$ increased. When the $\mathrm{pH}$ is higher than 6 , the zeta potential was more than $-20 \mathrm{mV}$ and achieves a value of $-30.3 \mathrm{mV}$ at $\mathrm{pH} 10$. The zeta potential of $\pm 30 \mathrm{mV}$ was reported to be sufficiently negative for electrostatic stabilization of colloidal nanoparticles [13]. On the other hand, electrostatic energy also depends on particle size and the larger the particle, the higher the energy [14]. In the case of Au/alginate nanocomposite, the $\mathrm{pH}$ of solution during the synthesis could affect the particle size of the assynthesized nanocomposite. At lower $\mathrm{pH}$, interaction between alginate molecules were more pronounced since a large number of hydrogen bonding was formed between alginate molecules. These molecules were attached to $\mathrm{Au}$ nanoparticles surface, so that the shorter the alginate-alginate distance, the shorter the particle-particle separation distance. As a result, agglomeration between particles could not be hindered.

Fig. $2 \mathrm{~A}$ revealed that the zeta potential played a significant role in the electrostatic stabilization. The higher the zeta potential, the more intensive the repulsion, as it can be seen from the higher the repulsion energy. The high repulsion energy favored the colloidal stabilization since it leads to the more positive of the total energy. 

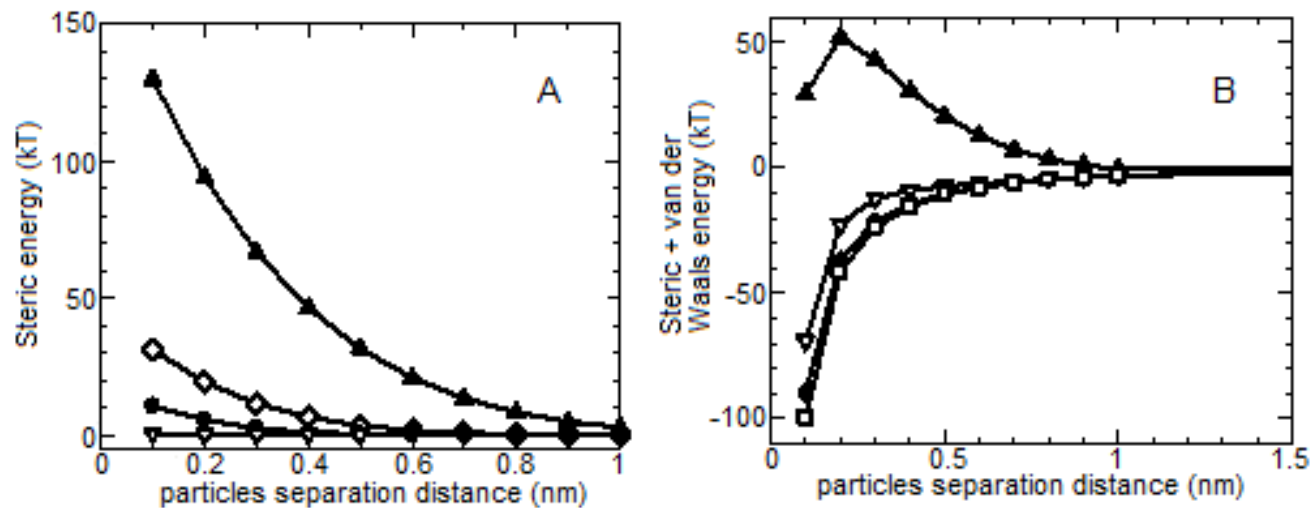

Fig 4. A. Steric energy curve for Au/alginate nanocomposite at various $L, B$. The combination of van der Waals and steric energy at various $\mathrm{L} ; \mathrm{L}=0.25,0.50,0.75,1.00 \mathrm{~nm}$, from bottom to top

According to the study, it was found that the zeta potential was influenced by $\mathrm{pH}$. As the $\mathrm{pH}$ increased, the zeta potential was also increased until $\mathrm{pH} 10$ (Table 1, Fig. 3). It explained the fact that the system was more stable in the higher $\mathrm{pH}$, resulting the smaller particle size. At $\mathrm{pH}$ 2, Au/alginate nanocomposite were successfully synthesized but yielded in the low stable particles. The colloidal nanoparticles at this condition were violet and the particle size distribution was very wide. The analysis of particle size distribution showed three peaks of particle size curve: $16.36 \mathrm{~nm}(82.9 \%$ volume), $91.41 \mathrm{~nm}$ (3.1\% volume), $257.1 \mathrm{~nm}(3.5 \%$ volume). When $\mathrm{pH}$ was 10 , at the same alginate concentration $(0.25 \%(\mathrm{w} / \mathrm{v}))$, the particle size of Au/alginate was $4.828 \mathrm{~nm} \quad(80.3 \%$ volume $)$ and $13.230 \mathrm{~nm}$ (19.3\% volume).

Fig. 2B showed the sum of electrostatic and van der Waals which has negative values at shorter particleparticle distance. It means that electrostatic energy alone was not sufficient to act as energy barrier for counteracting the van der Waals attraction forces at the distance. At longer particle-particle separation distance, the electrostatic energy became higher and has positive values. Compared to the steric stabilization energy, which will be discussed later, this electrostatic energy was relatively low.

\section{Steric energy}

In the colloidal system studied here, alginate was not only act as reducing agent but also as stabilizer since the bulky structure of alginate chain could arrange themselves on the particle surface forming polymer layer. The polymer layer prevents the particles from approaching each other closely enough for the van der Waals attractions to cause aggregation. An understanding of how the forces between two polymercoated nanoparticles depend on the various molecular parameters, such as the molecular weight of the chains and their interaction with the suspending fluid, is crucial to creating nanocomposite materials with welldispersed nanoparticles [15].

The strength of repulsion between the biopolymer chains can be predicted by mathematical calculation of steric repulsion energy. Steric repulsion energy is the combination of mixing energy $\left(E_{\text {mix }}(h)\right)$ and elastic energy $\left(E_{\text {elastic }}(h)\right)$, which is stated as equation 6 and 7. Different from the mixing repulsion which is due to interpenetration of two polymer layers, elastic repulsion energy results from the entropy loss due to compression of the coating layer of polymer tails between two metal cores [16].

$E_{\text {mix }}(h)=\frac{32 \pi k T a}{5 v} \frac{V_{f}^{2}}{L^{4}}\left(\frac{1}{2}-\chi\right)\left(L-\frac{h}{2}\right)^{6}$

At small particle-particle separation $(\mathrm{h}<\mathrm{L})$, the polymer segment density is assumed to be uniform and the contributions from the elastic and mixing interactions are given by,

$$
\begin{aligned}
& E_{\text {mix }}(h)=\frac{4 \pi a k T L^{2}}{V} V_{f}^{2}\left(\frac{1}{2}-\chi\right)\left(\frac{h}{2 L}-\frac{1}{4}-\ln \frac{h}{L}\right) \\
& E_{\text {elassic }}(h)=\frac{2 \pi a k T L^{2}}{M_{w}} V_{f}^{2}\left\{\ln \left[\ln \left[\frac{h}{L}\left(\frac{3-\frac{h}{L}}{2}\right)^{2}\right]\right\}-6 \ln \left(\frac{3-\frac{h}{L}}{2}\right)+3\left(1-\frac{h}{L}\right)\right.
\end{aligned}
$$

where $V_{f}$ is the average volume fraction of the polymer segments in the adsorbed layer, $L$ is the adsorbed polymer layer thickness, $v$ is the molecular volume of the dispersing medium, and $\chi$ is the Flory-Huggins parameter. $E_{\text {elastic }}(h)$ is the polymer chain elastic interaction energy, $\rho$ is the density and $M_{\mathrm{w}}$ is the molecular weight of the adsorbed polymer.

By applying particle radius of $2.414 \mathrm{~nm}$ (optimum condition of Au/alginate nanocomposite) and various $L$ in the range of $0.25-1.00 \mathrm{~nm}$, the value of $V_{f}$ can be calculated by assuming that all of particles were spherical in shape. $v$ is $2.99 \times 10^{-29} \mathrm{~m}^{3}$ for water as dispersing medium, and $\chi$ for alginate is 0.24 [17]. 


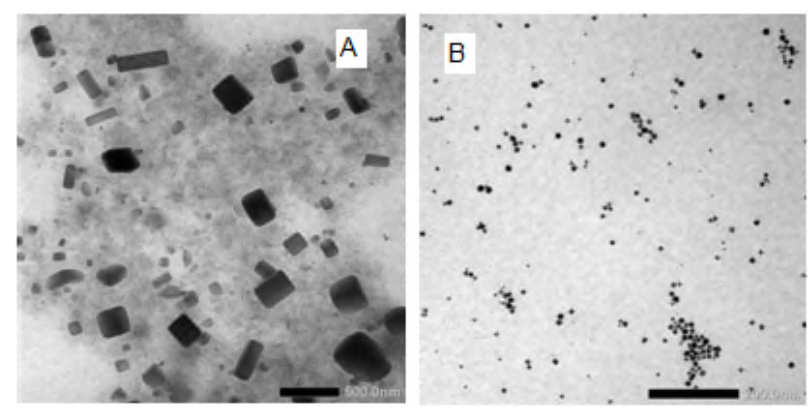

Fig 5. TEM image for Au/alginate nanocomposite synthesized at alginate concentration of $0.075 \%(w / v)(A)$ and $0.25 \%(\mathrm{w} / \mathrm{v})(\mathrm{B})$. Scale bar are $500 \mathrm{~nm}(\mathrm{~A})$ and $200 \mathrm{~nm}(\mathrm{~B})$
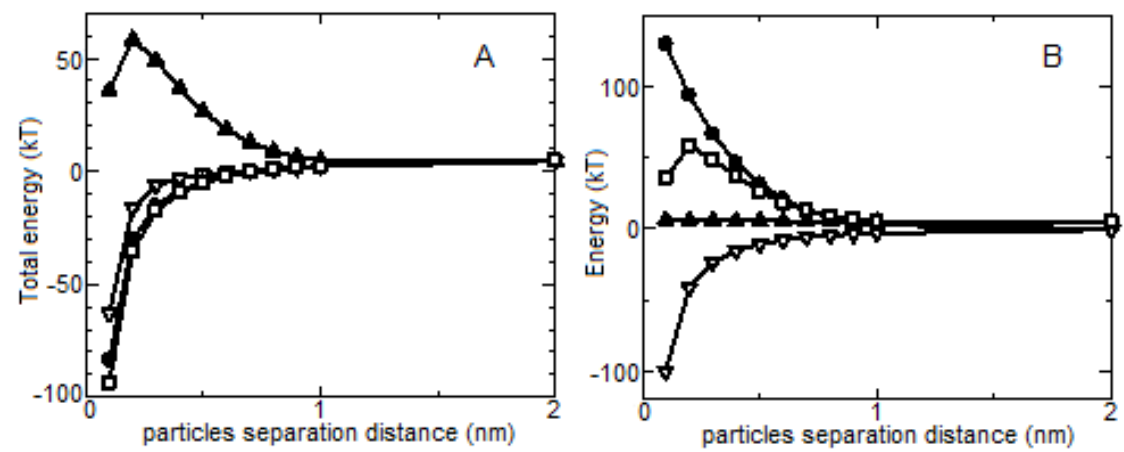

Fig 6. A. The combination of van der Waals, steric and electrostatic (at zeta potential $=-30.33 \mathrm{mV}$ ) energy at various $L(L=0.25 ; 0.50 ; 0.75 ; 1.00 \mathrm{~nm}$, from bottom to top), B. Steric energy $(L=10 \mathrm{~nm})(\bullet)$, total energy $(\square)$, electrostatic energy (at zeta potential $-30.33 \mathrm{mV})(\mathbf{\Lambda})$, and van der Waals energy $(a=2.414 \mathrm{~nm})(\nabla)$

Fig. 4A showed that alginate layer thickness $(\mathrm{L})$ has strong effect to the steric repulsion energy. When $L$ was low, at shorter particle-particle separation distance, the steric energy was zero. At higher L, the steric energy was drastically raised and achieved a value of more than $100 \mathrm{kT}$ at $\mathrm{L}$ of $1.00 \mathrm{~nm}$. Besides that, the steric energy effective range was increased substantially as $L$ increased. If the steric energy was mixed with van der Waals energy, it could be seen that the minimum $L$ required for hindering the van der Waals attraction between particles was $1.00 \mathrm{~nm}$ (Fig. 4B). Below this value, the sum of the two types energies have negative values at shorter particle-particle separation distance and approached zero at longer distance. The steric repulsion energy was sufficiently high at the great alginate layer thickness due to high molecular weight of alginate and the long chain of this polymer may likely be effectively adsorbed onto particle surface, and created repulsion between polymer-capped particles.

Since the alginate layer thickness depends on alginate concentration applied in the synthesis, the above mathematical calculation implied that applying high alginate concentration should be considered to achieve high stability of the as-synthesized nanoparticles. This statement was in agreement with the result of the experiment that at low alginate concentration $(0.05-0.075 \%(w / v))$, the colloidal
Au/alginate nanocomposites were not stable and the SPR spectrum was broadened at higher wavelength. At alginate concentration above $0.25 \%(\mathrm{w} / \mathrm{v})$, formation of stable colloidal Au/alginate nanocomposites was very probable to occur. The TEM image (Fig. 5A) showed that at the same storage time ( 2 months), colloidal Au/alginate nanocomposites synthesized at low alginate concentration aggregated into large particles and produced nonspherical particle shape, which is cubic and rodlike shape in this case. This phenomenon was not occurred at high alginate concentration, as shown in Fig. 5B. After 2 months, the colloidal Au/alginate nanocomposites were still spherical in shape, and did not significantly form any aggregates.

\section{Total energy}

The trends of the total energy (the sum of van der Waals, steric and electrostatic energy) shown in Fig. 6A was not significantly different from that of the steric energy, since the contribution of the electrostatic energy was much lower than that of the steric energy. In the synthesis, the effect of steric and electrostatic repulsion on the colloidal Au/alginate stabilization could be assessed by comparing the effect of $\mathrm{pH}$ and alginate concentration on the particle size of the asprepared nanoparticles. Although $\mathrm{pH}$ was adjusted to a moderately high value ( 6 or above), if the alginate 
concentration was too low, the particle size was relatively large. These data stated below explained this trend. By using higher alginate concentration $(0.375 \%(w / v))$, at $\mathrm{pH} 2$, the particle size was $9.819 \mathrm{~nm}$ (89.4\% volume), whereas at the same $\mathrm{pH}$, using alginate concentration of $0.25 \%(\mathrm{w} / \mathrm{v})$, a large number particle have the size of $16.36 \mathrm{~nm}$ and $91.41 \mathrm{~nm}$, as has been discussed above. At $\mathrm{pH} 6$, using the lower alginate concentration, $0.15 \%(\mathrm{w} / \mathrm{v})$, the particle size was $19.64 \mathrm{~nm}$ (98.8\% volume), but when the alginate concentration raised to $0.375 \%(\mathrm{w} / \mathrm{v})$, the particle size was significantly dropped to $5.46 \mathrm{~nm}$ ( $98.0 \%$ volume).

In this system, as shown by the interaction energy curve, the stabilization of colloidal nanocomposite system was not effective if only relying on electrostatic repulsion energy. One of the techniques to improve the electrostatic stabilization mechanism is by reducing the valency and concentration of electrolytes present in the system. The minimum $\mathrm{z}$ is 1 for $\mathrm{HCl}$ and $\mathrm{NaOH}$ and it can not be further minimized. Another alternatives is reducing the quantities of $\mathrm{HCl}$ and $\mathrm{NaOH}$ to increase $1 / \kappa$, but this treatment lead to another problem. First, it is difficult to adjust an appropriate $\mathrm{pH}$ for effectively reducing metal precursor which yields optimum characteristic of the as-produced nanocomposites. Second, it is difficult to obtain high value of potential zeta on the particle surface, as required for obtaining high electrostatic energy.

Besides due to the higher capacity in the stabilizing nanocomposites against aggregation (as compared to electrostatic repulsion), it is found that the steric energy is relative insensitive to the variation of solution chemistry, neither ionic strength nor the surface potential. Those advantages explain the reason why the steric stabilization is widely employed in the synthesis or preparation of colloidal particle suspensions [18].

Though the above explanation is merely a simplified statement from an exact mathematical equation for the real system (which should involve each contribution of all interaction type works on the system), it provides an important suggestion related with the variables which should be controlled in order to yield excellent stability of the as-synthesized nanocomposites.

\section{CONCLUSION}

According to the calculation of interaction energies in the colloidal system of Au/alginate nanocomposite, it can be concluded that both steric and electrostatic stabilization played a crucial role to avoid interparticle aggregation, but the steric stabilization give higher contribution than the electrostatic stabilization due to the larger molecular weight of alginate. It can be implied that the formation of highly stable of Au/alginate nanocomposite can be achieved by adjusting both the alginate layer thickness and $\mathrm{pH}$.

\section{ACKNOWLEDGEMENT}

This work was funded by Hibah Penelitian Kompetensi (National Competitive Research), Directorate General of Higher Education, Ministry of National Education Indonesia through The Directorate of Research and Community Services, Universitas Indonesia, Indonesia.

\section{REFERENCES}

1. Liang, Y., Hilal, N., Langston, P., and Starov, V., 2007, Adv. Colloid Interface Sci., 134-135, 151166.

2. Moreno-Atanasio, R., Antony, S.J., and Williams, R.A., 2009, Particuology, 7 (2), 106-113.

3. Lu, K., 2008, Ceram. Int., 34 (6), 1353-1360.

4. Rakhshaee, R., 2011, J. Hazard. Mater., 197, 144152.

5. Pal, A., and Kunio, E., 2007, J. Nanosci. Nanotechnol., 7 (6), 2110-2115.

6. Kora, A.J., Sashidhar, R.B., and Arunachalam, J., 2010, Carbohydr. Polym., 82 (3), 670-679.

7. Pandey, S., Goswami, G.K., and Nanda, K.K., 2012, Int. J. Biol. Macromol., 51 (4), 583-589.

8. Sen, I.K., Maity, K., and Islam, S.S., 2013, Carbohydr. Polym., 91 (2), 518-528.

9. Romero-Cano, M.S., Martín-Rodríguez, A., and de las Nieves, F.J., 2001, Langmuir, 17 (11), 35053511.

10. Bargeman, D., and van Voorst Vader, F., 1972, J. Electroanal. Chem., 37 (1), 45-52.

11. Das, S., Sreeram, P.A., and Raychaudhuri, A.K., 2007, Nanotechnology, 18 (3), 035501.

12. Gu, Y., 2001, J. Adhes. Sci. Technol., 15 (11), 1263-1283.

13. Leite, E.R., and Ribeiro, C., 2012, Crystallization and Growth of Colloidal Nanocrystals, SpringerBriefs in Materials, DOI 10.1007/978-14614-1308-0_2, 15.

14. Fendler, J.H., 1998, Nanoparticles and nanostructured films: preparation, characterization and applications, Wiley-VCH, New York, Chichester, Brisbane, Singapore, Toronto.

15. Frischknecht, A.L., 2008, J. Chem. Phys., 128 (22), 224902.

16. Klein, J., Stock, J., and Vorlop, K.-D., 1983, Eur. J. Appl. Microbiol. Biotechnol., 18 (2), 86-91.

17. Lin, S., and Wiesner, M.R., 2012, Chem. Eng. J., 191, 297-305.

18. Lin, S., and Wiesner, M.R., 2012, Langmuir, 28 (43), 15233-15245. 